\title{
The renal pathology in a case of lithium-induced diabetes insipidus
}

\author{
G. B. M. LINDOP AND P. L. PADFIELD
}

From the Department of Pathology, and MRC Blood Pressure Unit, Western Infirmary, Glasgow G11 6NT

SYNOPSIS A case of lithium-induced diabetes insipidus is reported. At necropsy microscopy showed unique and extensive damage to cells lining the distal nephron. It is suggested that these changes represent a specific toxic effect of lithium, reported here for the first time in man.

Lithium carbonate is widely used in psychiatric practice in the treatment of manic depressive psychosis. The toxic effects of lithium ion have been known since lithium chloride was used as a salt substitute for patients on low sodium diets 25 years ago. These are well reviewed by Schou (1968). Among the reported toxic effects is a diabetes insipidus-like state of polyuria and polydipsia (Forrest et al, 1974). Histopathological studies of the kidney in patients with this manifestation of lithium toxicity have been carried out both by renal biopsy (Schou et al, 1968) and at necropsy in fatal cases (Schou et al, 1968; Chapman and Lewis 1972). The results of these studies have been mostly negative. This paper presents a case report of lithium toxicity with diabetes insipidus, showing histological evidence of unusual damage to the cells lining the distal nephron. This appears to be the first time that such changes have been described in man.

\section{Case Report}

A 27-year-old man had suffered from manic depressive psychosis for ten years. In March 1970, he was started on prophylactic treatment with lithium carbonate, initially in a dose of $1.2 \mathrm{~g}$ per day, rising to $2.2 \mathrm{~g}$ per day. Estimation of the serum lithium levels was performed at approximately monthly intervals, and at no time did the serum level exceed $1.2 \mathrm{mEq}^{-1}$. Eleven months after starting lithium therapy he began to develop increasing polyuria and polydipsia, until, at the time of investigation in 1973, he was passing some 6-9 litres of urine per day.

On admission to hospital physical examination revealed an obese man with a blood pressure of $170 / 80 \mathrm{mmHg}$. Routine investigations showed normal serum electrolytes, urea, creatinine, calcium, and blood glucose. Skull and chest radiographs and an intravenous urogram were also normal. Serum lithium levels were 1.0 and $1.1 \mathrm{mEq}^{-1}$ (therapeutic range 0.6-1.6 $\mathrm{mEq} \mathrm{1}^{-1}$ ) (Schou and Baastrup, 1967).

The patient was shown to be suffering from diabetes insipidus by his failure to concentrate his urine adequately following fluid deprivation. That this was the nephrogenic form of the disease was shown by the finding of high basal levels of plasma arginine vasopressin, which rose on fluid deprivation, and the almost total lack of ability to concentrate urine following an infusion of synthetic arginine vasopressin. The investigations are reported in detail elsewhere (Padfield et $a l$, in press).

Further investigations were prevented by the patient's death following presumed self-poisoning.

\section{Renal Pathology}

Slices of tissue were obtained from the kidneys at 윽 necropsy and fixed in the usual way with $10 \% \frac{D}{2}$ formol saline, the kidneys being macroscopically normal.

On histological examination there was no evidence of any incidental renal or renovascular pathology which may have predisposed to a toxic accumulation $\omega$ of lithium. The histological preservation of the kidney was good, and this permitted the detection 0 of an unusual change in the cells lining the distal $\mathbb{D}$ nephron. There was marked cellular pleomor-? phism; many of the cells were small and had small 0 pyknotic irregular nuclei, while others were very

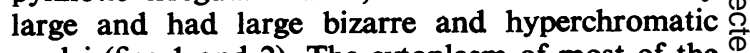
nuclei (figs 1 and 2). The cytoplasm of most of the $\stackrel{\mathbb{Q}}{\varrho}$ altered cells was eosinophilic and granular. In many places the epithelium was disrupted and the cells could be seen leaving the basement membrane to 


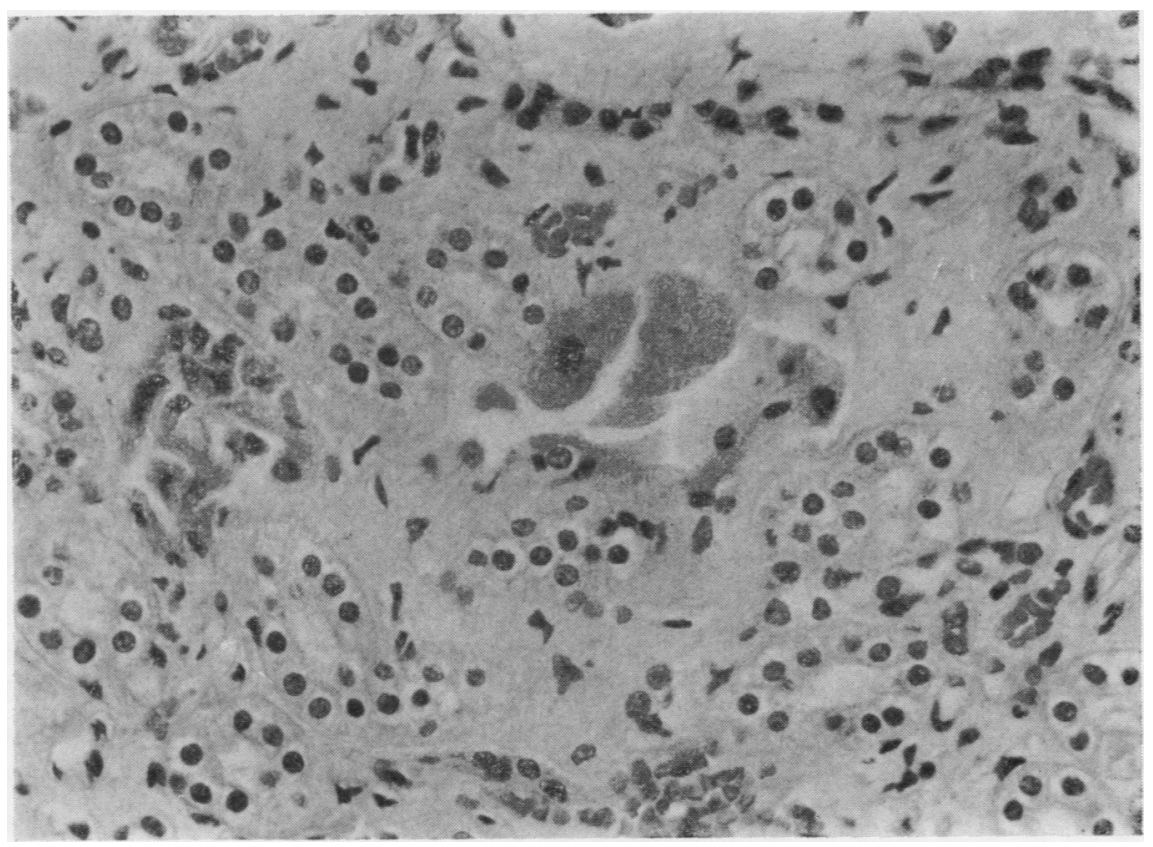

Fig 1 Renal medulla showing two structures, probably collecting ducts, lined by pleomorphic altered epithelium. Many of the cells are abnormally large with a markedly granular cytoplasm. $H$ and $E \times 188$.

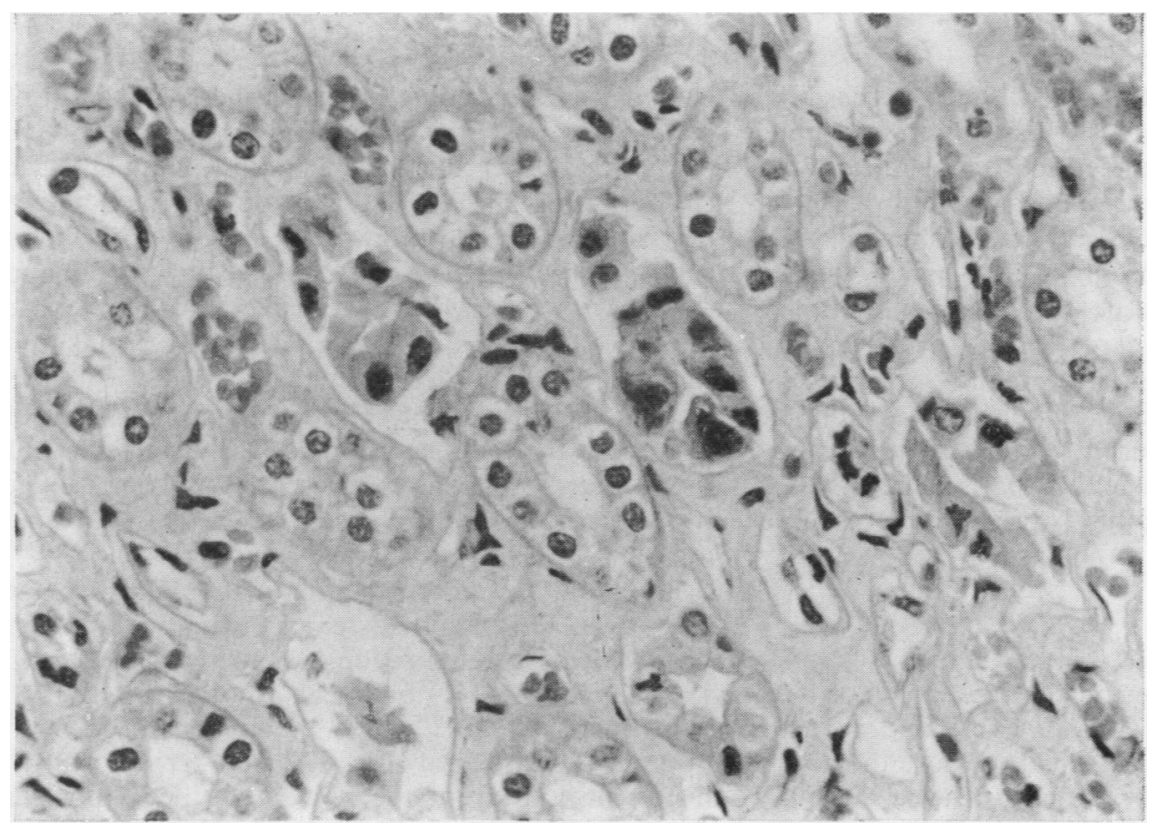

Fig 2 Renal medulla showing damaged epithelium with hyperchromatic nuclei and a high nucleus/cytoplasm ratio. Some of the epithelium in loops of Henle shows nuclear pyknosis. $H$ and $E \times 300$. 


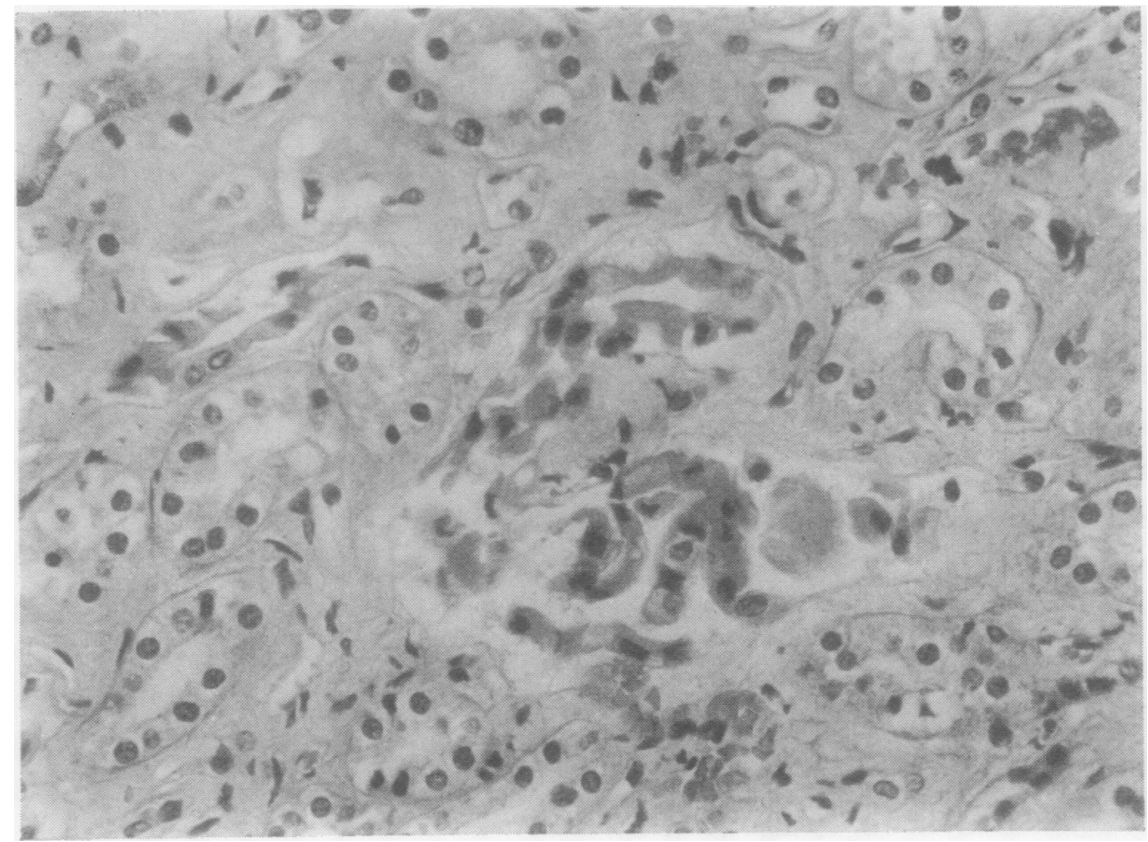

Fig 3 Renal medulla showing probably a collecting duct, with damaged epithelium leaving the basement membrane and lying free in the lumen. Occasional other structures, probably loops of Henle, show nuclear pyknosis and cytoplasmic eosinophilia. $H$ and $E$ $\times 188$.

form cellular casts in the lumen (fig 3). Occasional tubules were lined only by basement membrane (fig 2). These severely damaged collecting ducts could be seen surrounded by more normal loops of Henle. Very scanty mitotic figures were seen. These changes affected mainly the collecting ducts, but less severe changes were present in the distal convoluted tubule and the ascending loop of Henle. In these latter sites the changes consisted mainly of nuclear pyknosis. No significant abnormality could be detected in the glomeruli, proximal tubules or descending loops of Henle. No viral inclusions were seen. The damage was diffusely present in all sections examined.

\section{Discussion}

Lithium induces nephrogenic diabetes insipidus both in animals (Radomski et al, 1950) and in man (Forrest et al, 1974). It specifically blocks the action of adenosine diphosphate in altering the permeability of the distal tubule in rats (Harris and Jenner, 1972) and in man (Singer et al, 1972). The mechanism of this end-organ unresponsiveness is as yet unknown. Direct damage to the distal nephron is one possible explanation. In keeping with this, there is a report of histological evidence of damage to the cells of the distal nephron in dogs infused with lithium chloride (Radomski et al, 1950). This unillustrated paper describes the collecting ducts, distal convoluted tubule, and distal loop of Henle as being dilated and 'lined with atypical reparative epithelium'. The scantiness of the histological description makes it difficult to make a direct comparison with the lesions present in our patient. Ultrastructural evidence of damage to the distal nephron has also been described in the rat (Evan and Ollerich, 1972). The damage was dose-related and most marked in the collecting ducts.

Schou (1958) described proximal tubule damage in the rat. Other animal toxicity studies, however, have shown no renal lesions in rats (MacLeod et al, 1949; Talbott, 1950) or in cats (Good, 1903).

In man, while $12 \%$ of patients treated with lithium develop polyuria (Forrest et al, 1974), histological study of the kidney has been thus far unhelpful. Patients with polyuria due to lithium therapy have been subjected to renal biopsy with negative results. In this series necropsy studies of fatal cases of lithium toxicity showed incidental renal 
or renovascular disease which may possibly have predisposed to a toxic accumulation of the drug, since urinary excretion is the main form of elimination of lithium from the body (Schou, 1968). There was no evidence of distal tubular damage nor any specific lesion induced by lithium.

Renal tubular damage and interstitial oedema were described in a necropsy report of a fatal case of lithium toxicity by Chapman and Lewis (1972). However, these authors found it difficult to distinguish tubular damage from post-mortem autolysis. The unusual distal tubule changes described here were not present, and the authors concluded that their findings of necrosis of the proximal and distal tubules and interstitial oedema were non-specific. The finding of distal nephron lesions in our patient has not previously been described in man, and is in keeping with the reported toxic effect of lithium in dogs (Radomski et al, 1950) and in rats (Evan and Ollerich, 1972).

The urinary concentration studies performed on our patient and reported in detail elsewhere (Padfield et al, in press) provide evidence that the diabetes insipidus induced by lithium is nephrogenic in type. The ability of the kidney to produce concentrated urine is a function of the loops of Henle and the collecting ducts. Thus when a pathological process damages the vasculature or the architecture of the medulla, concentrating ability is lost. This has been shown to occur in such predominantly medullary diseases as pyelonephritis (Raaschou, 1943; Relman and Levinsky, 1961), experimental phenacetin nephropathy (Angervall et al, 1964), sickle cell disease (Statius van Eps et al, 1970), and medullary cystic disease (Giselson et al, 1970). It is suggested that the extensive medullary damage reported here and in the animal experiments noted above may be a specific effect of lithium and that this damage may form a morphological expression of the nephrogenic diabetes insipidus induced by lithium.

\section{References}

Angervall, L., Lehmann, L., and Bengtsson, U. (1964). The renal concentrating capacity in albino rats after long-term consumption of phenacetin, NAPA (N-acetyl-p-aminophenol) and acetylsalicylic acid. Acta med. scand., 175, 155-160.

Chapman, A. J. and Lewis, Gillian (1972). Iatrogenic lithium poisoning; a case report with necropsy findings. J. Okla. med. Ass., 65, 491-494.

Evan, A. P. and Ollerich, D. A. (1972). The effect of lithium carbonate on the structure of the rat kidney. Amer. J. Anat., 134, 97-106.

Forrest, J. N., Jr., Cohen, A. D., Torretti, J., Himmelhoch, J. M., and Epstein, F. H. (1974). On the mechanism of lithium-induced diabetes insipidus in man and the rat. J. clin. Invest., 53, 1115-1123.

Giselson, N., Heinegard, D., Holmberg, C. G., Lindberg, L. G., Lindstedt, E., Lindstedt, G., and Schersten, B. (1970). Renal medullary cystic disease or familial juvenile nephronophthisis. Amer. J. Med., 48, 174-184.

Good, C. A. (1903). An experimental study of lithium. Amer. J. med. Sci., 125, 273-284.

Harris, C. A. and Jenner, F. A. (1972). Some aspects of the inhibition of the action of antidiuretic hormone by lithium ions in the rat kidney and bladder of the toad Bufo marinus. Brit. J. Pharmacol., 44, 223-232.

MacLeod, J., Swan, R. C., and Aitken, G. A., Jr. (1949). Lithium: its effect on human spermatozoa, rat testicular tissue and upon rats in vivo. Amer. J. Physiol., 157, 177-183.

Padfield, P. L., Morton, J. J., Lindop, G., and Timbury, G. C. (1975). Lithium-induced nephrogenic diabetes insipidus: changes in plasma vasopressin and angiotensin II. Clinical Nephrology, in press

Raaschou, F. (1943). Dissociation between glomerular and tubular renal function in cases of pyelonephritis. Acta med. scand., 114, 414-425.

Radomski, J. L., Fuyat, H. N., Nelson, A. A., and Smith, P. K. (1950). The toxic effects, excretion and distribution of lithium chloride. J. Pharmacol. exp. Ther., 100, 429-444.

Relman, A. S. and Levinsky, N. G. (1961). Kidney disease: acquired tubular disorders. Ann. Rev. Med., 12, 93-110.

Schou, M. (1958). Lithium studies: 1. Toxicity. Acta Pharmacol $(K b h), 15,.70-84$.

Schou, M. (1968). Lithium is psychiatric therapy and prophylaxis. J. Psychiat. Res., 6, 67-95.

Schou, M., Amdisen, A., and Trap-Jensen, J. (1968). Lithium poisoning. Amer. J. Psychiat., 125, 520-527.

Schou, M. and Baastrup, P. C. (1967). Lithium treatment of manic-depressive disorder. J. Amer. med. Ass., 201, 696698.

Singer, I., Rotenberg, D., and Puschett, J. B. (1972). Lithium induced nephrogenic diabetes insipidus: in vivo and in vitro studies. J. clin. Invest., 51, 1081-1091.

Statius van Eps, L. W., Pinedo-Veels, C., de Vries, H. H., and de Koning, J. (1970). Nature of concentrating defect in sickle-cell nephropathy. Lancet, 1, 450-452.

Talbott, J. H. (1950). Use of lithium salts as a substitute for sodium chloride. Arch. intern. Med., 85, 1-10. 